\title{
Magnetic Resonance Imaging in Osmotic Demyelination Syndrome
}

\section{Clinical image}

A 52-year-old man on several anti-hypertensives including Hydrochlorothiazide and Spironolactone presented with confusion and intestinal obstruction. He had profound hyponatremia with serum sodium of $96 \mathrm{mmol} / \mathrm{L}$; this was attributed to the diuretics he was prescribed. Clinical improvement were seen over the next six days with gradual correction of serum sodium at a rate of around 4 $\mathrm{mmol} / \mathrm{L} / \mathrm{day}$, from $96 \mathrm{mmol} / \mathrm{L}$ to $124 \mathrm{mmol} / \mathrm{L}$. However, over the following three days, serum sodium increased further from 124 $\mathrm{mmol} / \mathrm{L}$ to $147 \mathrm{mmol} / \mathrm{L}$. Approximately 48 hours after the rapid increase in serum sodium, his Glasgow Coma Scale decreased indicating low conscious level, thus necessitating intubation. Serum sodium levels stabilised thereafter, but there were no improvement in conscious level. The patient appeared to be in a 'locked-in' state. Magnetic Resonance Imaging (MRI) (shown below) revealed central pontine and extrapontine myelinolysis with $\mathrm{T} 2$ hyperintensity at the pons (Trident sign) (A) as well as the putamen and caudate nucleus (B) and restricted diffusion on Diffusion Weighted Imaging (DWI) mapping (C) and Apparent Diffusion Coefficient (ADC) mapping (D). These are radiological features, which has been described. ${ }^{1-3}$ Plasma exchange was done, but he showed no significant neurological recovery (Figure $1 \& 2$ ).

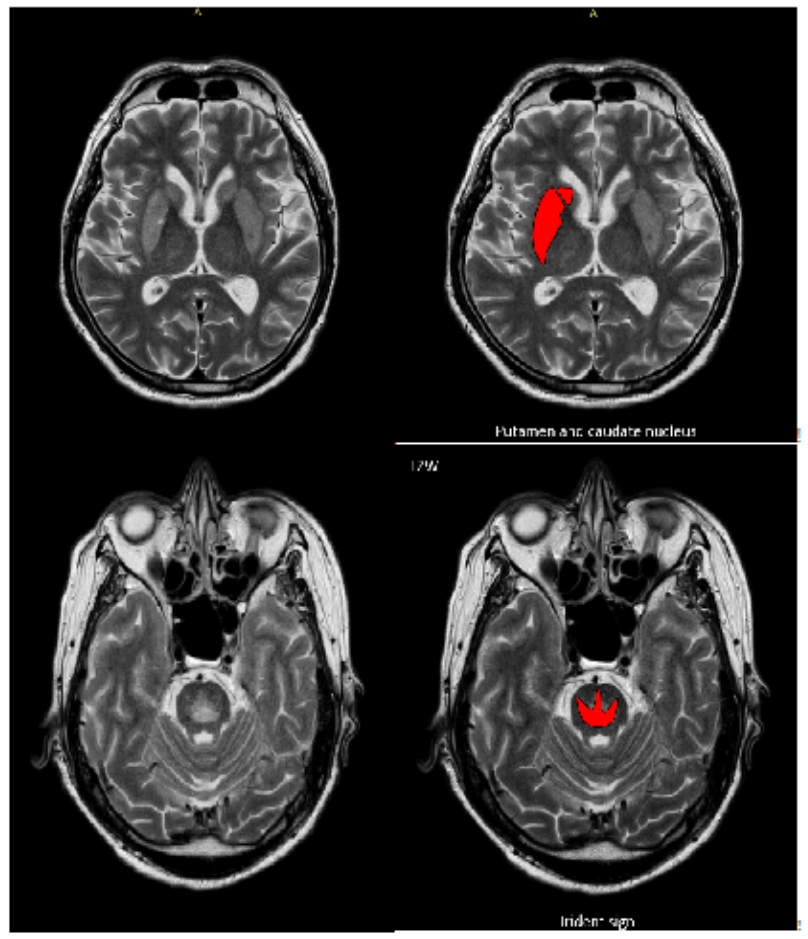

Magnetic Resonance Imaging (MRI) revealed central pontine and extrapontine myelinolysis with T2 hyperintensity at the pons as well as the putamen and caudate nucleus
Volume 10 Issue 4 - 2020

Presaad Pillai, Joyce Pauline Joseph

Department of Neurology, Kuala Lumpur Hospital, Malaysia

Correspondence: Presaad PILLAI, Kuala Lumpur Hospital, Department of Neurology, Kuala Lumpur, Malaysia,Tel +60326155555, Email presaad87@gmail.com

Received: June 122020 | Published: July 06, 2020

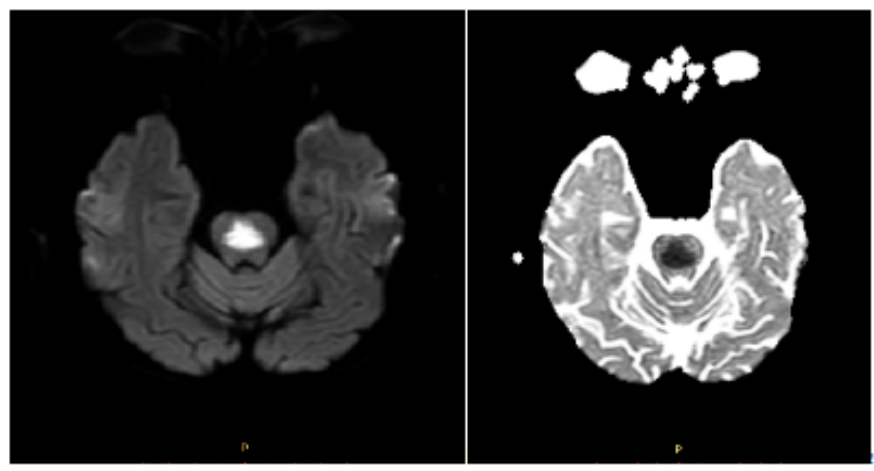

Diffusion Weighted Imaging (DWI) mapping and Apparent Diffusion Coefficient (ADC) mapping

\section{Acknowledgments}

None.

\section{Conflicts of interest}

The author declares no conflicts of interest.

\section{References}

1. Brown WD. Osmotic demyelination disorders: Central pontine andextrapontine myelinolysis. Curr Opin Neurol. 2000;13(6):691-697.

2. Anthony M Alleman. Osmotic Demyelination Syndrome: Central Pontine Myelinolysis and Extrapontine Myelinolysis. Semin Ultrasound CT M. 2014;35(2):153-159.

3. S Huq, M Wong, H Chan, et al. Osmotic demyelination syndromes: Central and extrapontine myelinolysis. JClin Neurosci. 2007;14(7):684 688. 